\title{
Social Bookmarking Tools as Facilitators of Learning and Research Collaborative Processes: The Diigo Case
}

\author{
Enrique Estellés \\ Department of Mathematics, \\ Physics and Computation, \\ CEU-Cardenal Herrera University, \\ Valencia, Spain \\ kikeestelles@gmail.com
}

\author{
Esther del Moral \\ Department of Education \\ Science, \\ University of Oviedo, Spain \\ emoral@uniovi.es
}

\author{
Fernando González \\ Department of Management, Technical University of Valencia, \\ Valencia, Spain \\ fgonzal@omp.upv.es
}

\begin{abstract}
Material published as part of this publication, either on-line or in print, is copyrighted by the Informing Science Institute. Permission to make digital or paper copy of part or all of these works for personal or classroom use is granted without fee provided that the copies are not made or distributed for profit or commercial advantage AND that copies 1) bear this notice in full and 2) give the full citation on the first page. It is permissible to abstract these works so long as credit is given. To copy in all other cases or to republish or to post on a server or to redistribute to lists requires specific permission and payment of a fee. Contact Publisher@InformingScience.org to request redistribution permission.
\end{abstract}

Web 2.0 has created new applications with remarkable socializing nuance, such as the SBS (Social Bookmarking Systems). Rather than focusing on the relationship between users, the SBS provide users with the necessary tools to manage and use information that can later be shared.

This article presents a description, analysis, and comparison of different SBS, which are categorized as web applications that help to store, classify, organize, describe, and share multi-format information through links to interesting web sites, blogs, pictures, wikis, videos and podcasts. Also emphasized are the advantages for learning and collaborative research that SBS produce.

In this paper, Diigo will be specifically studied for its contribution as a metacognitive tool. Diigo shows the way each user learns, thinks, and develops the knowledge that was obtained from the information previously selected, organized, and categorized. Thus, the information becomes highly valuable, and knowledge is cooperatively built. This knowledge induces collaborative learning and research, since the tags that describe marked resources are shared between users. Consequently, they become meaningful learning resources that provide a social dimension to both

learning and online research processes.

Keywords: Social Bookmarking Systems, Folksonomies, Collaborative Research, Collaborative Learning.

\section{Introduction}

The rise of Web 2.0 tools has led to the rapid development of a number of applications that enhance collaborative work. These include social bookmarking sys- 
tems (SBS) that provide users with the reference (marked), description, classification and the possibility to share resources with other users.

In this paper, all the applications of SBS are addressed: functional features, nature, and restrictions. Next, one of these tools, Diigo, is analyzed, taking into account its possible uses and benefits for researching and education. In the fourth section, a comparison between different methods of storing bookmarks is carried out in order to highlight the advantages of Diigo and its differentiating features. This comparison is completed through a SWOT analysis of the kind of tools used in a 30-user community. To close, some conclusions and possible future directions of investigation are outlined.

\section{Social Bookmarking Systems}

Social Bookmarking Systems are web 2.0 tools that allow users to store, classify, organize, describe, and share links to interesting web sites, blogs, pictures, wikis, videos, and podcasts. They also guarantee access from any site to the conventional container of "favorite" links, as well as the possibility to share them with other like-minded users through blogs or RSS technology.

Depending on the web resources bookmarked, we can talk about different types of SBS. There are SBS focused on collecting web sites (Diigo, del.icio.es, Mister Wong, Blinklist), some focused on collecting news (digg.com), and others on pictures (Flickr) or even on bibliographical references (CiteU).

\section{Characteristics of Every SBS}

Regardless of the type of content tagged, all the above-mentioned SBS have some common characteristics. The most common of which are the basic unit of referenced information and the use of tags.

To begin with, the basic unit of referenced information used by any SBS is a set of three elements called 'triple' that is represented this way: (user, resource, \{tags\}) (Cattuto, 2006). This unit, which defines the way the SBS work, indicates that a user has marked a specific resource with a set of concrete tags.

As for the use of tags, it clearly implies the use of folksonomies. A folksonomy, a term coined by Thomas Vander Wal and which is a combination between "folk" and "taxonomy" (Smith, 2004), is an organic system of organization and a way of social classification using tags. Due to this, any SBS can also be seen as a Social Tagging System.

The folksonomy enables users to organize their bookmarks in a meaningful way and search for resources associated to specific tags. Resources can also be classified according to the number of users that have tagged them.

Unlike taxonomies (or classifications), where there are multiple types of hierarchical relationships, folksonomies are not based on hierarchies: there are no explicitly indicated relationships between the terms included. They are just the keywords that a group of users have used to describe a specific content (Hamond, Hannay, Lund, \& Scott, 2005; Mathes, 2004). The social networking usage of tags is one of the simplest ways of adding high-semantic-valued metadata to the content.

When a web resource is tagged, SBS enable users to describe its content by adding a set of data known as metadata (data about data). Depending on the SBS, this set of data or metadata contains the following elements (Zubiaga, Martínez, \& Fresno, 2009):

- Tags or terms that define and feature the resource. These can be names, acronyms, numbers, or any chain of text with no format or meaning restriction. 
- Notes or comments: a short text freely describing the content of the resource.

- Highlights: parts of the resource marked as relevant.

- Reviews: texts freely assessing the content of a resource.

- Ratings: personal marks or punctuation indicating whether users liked a specific resource or not in a scale from 1 to 5 , for instance.

In this way, folksonomies add high-semantic-valued metadata, which is especially relevant. In academic or research contexts, folksonomies help a scientific community of experts to add value to specific learning objects that are significant for collaborative projects. Thus, they help to enrich the learning community by creating and sharing sources of document resources.

According to Millen, Feinberg, and Kerr (2005), other common characteristics are:

- They enable users to create collections of bookmarks individually, classifying them as private (available only for the owner and for those users or groups he wants to invite) or public (available for everybody). Thanks to this characteristic, like-minded users can recover those collections by consulting categorized or tagged links.

- They help to create networks or groups of users interested in similar issues that share links through tag clouds, links to blogs and the possibility to subscribe through RSS to a specific user's account or to tags of interesting contents.

- Users can easily access them from any computer with Internet connection.

- They provide web browser complements that help to store and describe links.

- They use tags: keywords associated with a specific resource that are assigned by users.

- They include pivot browsing. This is a way of exploring, or re-orienting the selection of bookmarks and discovering information by navigating the collections of bookmarks filtered by users and tags (Bateman, Muller, \& Freyne, 2009; Millen, Whittaker, \& Yang, 2007).

Within the new functionalities of the different SBS, it must be also considered the storage of a 'snapshot' of the resource in the server or the suggestion of tags depending on the textual analysis of the content of the resource.

\section{Functions and Restrictions}

According to all that has been explained, SBS are useful tools for:

- Managing research groups focused on a specific topic. Researchers navigate the information that has been tagged by the 'collective intelligence' of those users that tagged and stored it previously.

- Organizing and managing relevant information for professors and researchers and also for university students. Therefore, folksonomies become a powerful tool for generating knowledge.

- Organizing, communicating and updating bibliographical lists or recommended readings, adding value to the shared information.

- Managing the information collected in any stage of the research process through the use of complements such as Zotero. Their collaborative nature makes them perfect tools for the cohesion of research groups.

- Searching for information directly related to the issue of interest for the group and the ability to access it. It has been proven that when looking for information via the links in SBS, like del.icio.us, newer or more updated contents of better quality can be found, compared to those that can be found through other search engines, e.g., Yahoo!, or direc- 
tories, e.g., Open Directory Project (ODP), (Kolay \& Dasdan, 2009). In spite of this, according to Heyman (2008), 25\% of the content collected by del.icio.us was not indexed by Yahoo!

Another interesting aspect about the usage of this tool is the fact that each member of a learning community can contribute to improving it. This is relevant in the academic and research field, where collective intelligence undoubtedly favours the advance and development of knowledge. By adding each user's contribution, the value of the knowledge increases, and, in this way, it is possible to learn from others simply by following the itineraries others have marked. Nevertheless, it must be taken into consideration that bookmarks have some technical restrictions. For example, a lack of homogeneity and agreement on how to define tags gives rise to ambiguities as Mathes (2004) points out: the use of subjective keywords (excessively personal ones that do not have the same meaning for the rest of users); the use of singular and plural words; the inconsistent usage of capital letters in different languages; the use of simple or complex words to define similar things, etc. In an attempt to solve these problems, in certain SBS there has been a common agreement on vocabulary. However, this solution has also its drawbacks, because sometimes the same tag is used with different meanings and the use of synonyms and acronyms leads to a greater confusion.

Despite the above-mentioned difficulties, SBS are useful for collaborative work because links are shared and metadata are cooperatively built.

Currently, experts are working to make SBS more powerful, enabling combined search techniques that integrate conventional search engines functions with those of SBS. An example of this is the plug-in (bookmarklet or browser extension) of the browser incorporated in the search toolbar that enables to associate Google's and Diigo's search. In the next section Diigo is described, and in the following section Diigo is compared to other SBS.

\section{Diigo Case}

\section{Description}

Diigo, an acronym for 'Digest of Internet Information, Groups and Other stuff', was launched in 2006, and after three years of development the Diigo company acquired Furl, which enabled it to grow in the field of SBS. Thanks to this growth, it has been recognized by the American Association of School librarians (AASL) as one of the Best Websites for Teaching and Learning (American Association of School Librarians, 2009), and referred to as a list of "tools and resources of exceptional value to inquiry-based teaching and learning."

Tags that define Diigo in Crunchbase give an idea of what Diigo exactly is: "ad-supportedsoftware", "social-bookmarking", "social-annotation", "social-information-network", "web-markup", "web-highlighter" and "web-sticky-notes".

Diigo is an application that allows the use of what is known as 'social annotation' through social bookmarking (SB), text annotations in-situ (in the web itself), tags describing the website, clipping (which allows videos to be marked), pictures or Flash animations- and a search in the whole text of the annotated pages (Diigo, 2006). All this information is stored in an Internet server allowing users to work with it from any computer with Internet connection, so that it is possible to share that material with other users. It is similar to Delicious, whose bookmarks can be imported by Diigo, but it has additional features that allow users to organize and show their presentations of bookmarks online through interactive slides that are open to public comments and annotations. 
Diigo is also a social network, but with some differences. It is an information social network, whose main objective is not enabling social interaction between users, but providing high-quality tools to recover, highlight, organize, and find information mainly for research tasks and for sharing with other users. It allows a close relationship between its two main components: users and information. The result of the possible relationships (user-user, user-information, informationinformation) achieves an improvement of the knowledge users share and an increase of the amount of available content and access to it., It also creates social connections based on preferences about specific type of information, allowing high-quality intellectual exchanges.

The meaning of Diigo suggests the different ways individuals can use it. Depending on that use, Diigo can be defined as a group research tool, as a sharing-knowledge community, or as a site with social content (Diigo, 2006).

Diigo allows effective and collaborative research because results can be shared by adding notes to the marked webs (electronic sticky notes) or highlighting. By doing this, a research team, a class, a club, or any other type of group can constitute a group in Diigo so that the users can share resources, relevant outcomes about an issue, or comments. As a site with social content, Diigo is based on the use of tags and online annotations about pages in order to make a repository of quality content, filtered and commented by the community (Heymann, Koutrika, \& Molina, 2008). Thus, a user can access a web site and see who else has marked it and which other sites with similar content have been found. This way of navigating, from link to link, is called 'social browsing.'

Finally, Diigo can be also understood as a community of users that share information. In this sense, inside Diigo 'you are what you highlight': the links you mark, the tags you use to describe them and the annotations you make. With all this information, Diigo enables people to connect very differently, in particular a user can be connected to 'people like me', matching based on recent bookmarks, so that he or she can meet like-minded users that are connected or interested in the same areas.

Regardless of the Diigo's various uses, Diigo provides users with a set of tools to manage bookmarks in order to work individually or collaboratively, which are explained in the next two sections.

\section{Functions for Individual Work}

Clearly, the main feature for individual work is, the capacity for managing bookmarks. In regards to this feature, Diigo offers 3 functionalities:

1. Importing bookmarks. Diigo imports the favorite sites of the browser as well as those of several SBS, for example Delicious, Simpy, Blinklist or Connotea. It also allows the importing of links that might have been stored in Google NoteBook.

2. Exporting bookmarks. Diigo allows the download of a file with marked resources in Internet Explorer, Netscape, RSS, CSV format or the format used by Delicious.

3. 'Save to del.icio.us'. Apart from exporting bookmarks with delicious format, as has already been stated, Diigo makes it possible for any web resource marked with Diigo Toolbar or Diigolet to also be stored automatically in del.icio.us. At the same time as a resource is marked in Diigo, it can also be marked in other SBS and even in the same browser simultaneously.

Diigo offers a series of complements for browsers that allow the marking of resources:

1. Diigo Toolbar (Figure 1). This toolbar can be installed in different browsers (Explorer, Firefox, Flock and Chrome). It has the following functionalities: it marks new resources 
(including describing tags), highlights parts of the web, marks the resources marked as 'non-read' and allows quick access to the resources stored in Diigo. This can be done in two different ways. One way is by using the 'smart folders', which are icons that display non-read resources, when the user clicks on them. The other way is by using the 'sidebar', which opens a small window embedded in the left of the page from where the user can start navigating through the resources stored in Diigo.

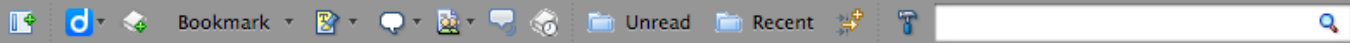

Figure 1: Diigo toolbar

2. Diigolet (Figure 2) is a complement similar to the Diigo Toolbar, and it can be applied to any browser (it is especially useful for those browsers incompatible with the Diigo Toolbar). It is a small script developed in javascript that creates a virtual toolbar associated to the web in which it is executed (when the user exits that page, Diigolet disappears). From this virtual toolbar the user can mark resources, highlight webs, add notes and comments and access Diigo web.

d Diigo Bookmark Highlight - $@$ Floating Sticky Note Comment Welcome kikeestelles (2) $\hat{\wedge}$

Figure 2: Diigolet virtual toolbar

3. 'Post to Diigo'. This complement must be put in the "favorites" toolbar that all browsers have. By doing this, when a resource that the user wants to be marked is found, the user only has to click on the button 'Post to Diigo' to add that resource to his bookmarks. It is actually a script of javascript that opens the Diigo page 'Add new Bookmark' and fills in the data of the title, etc., based on the available metadata of the resource.

4. Button 'add to Diigo' (Figure 3). This button must be placed next to publications (blogs, webs, news, etc.) and allows a user to mark that publication directly in Diigo, but this feature only works if the publication is a Diigo user.

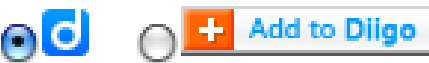

Figure 3: Button 'add to Diigo'

\section{Functions for Team Work}

1. Enhanced linkrolls (Figure 4). This is a list of marked web resources that can be shown, for example, in a user's personal web and can be filtered by tags. This complement enables a user to share marked resources so that visiting users, Diigo users or not, can see other users' comments and annotations when accessing a marked web. Through a web form, Diigo allows the user to define the number of resources to be shown, the colors to be used, etc. To summarize, it allows the customization of the list of resources and the creation of the corresponding code to be shown in any other web. As for the collaborative work, this tool keeps the visitors of the web where it is being used, informed about the last findings or interests of the user. 


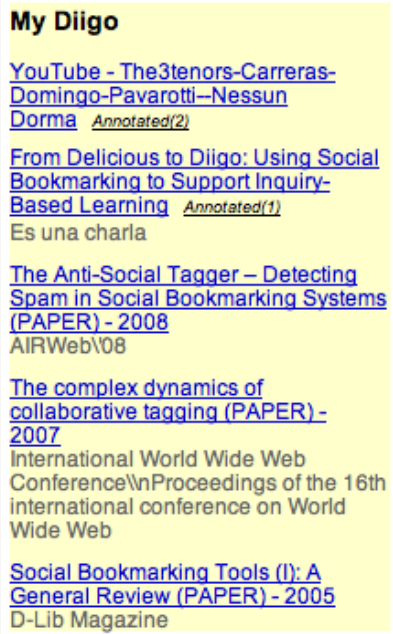

Figure 4: Enhanced linkrolls

2. Diigo TagRolls (Figure 5). Diigo is able to create tag clouds that may be inserted in a personal web or any other type of web. Like enhanced linkrolls, Diigo provides a form to customize the tag cloud and generate the corresponding code. With this tool, a user can show in a simple and intuitive way the topics in which he is interested or the ones he is currently working on. Visitors can then access his marked resources and start to interact.

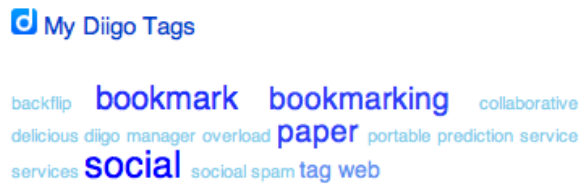

Figure 5: Diigo tagrolls

3. Send to blog. Diigo offers a button that complements the characteristics of highlighting text or adding notes. It sends the selected text to a blog that has been previously configured. In this way the contents that have been marked, highlighted or annotated enable visitors to access the blog where this content is published. Thus, communication between users and collaborative work is enhanced.

4. Auto blog post. This function works similarly to the previous one, but in an automatic and periodic way.

\section{Applications for Learning and Research}

In the university and research fields the following benefits are derived from Diigo:

- Enhances the cohesion of research groups on specific issues by navigating through information that has been tagged by researchers and/or users.

- Enables the organization and management of relevant information for professors as well as researchers, university students, etc. building knowledge cooperatively.

- Makes the organization, communication and updating of bibliographical references or specialized readings of interest more dynamic. It also makes specialized readings and references to which anybody can subscribe and re-tag incorporating new nuances. 
- Helps to manage information collected in the different stages of a research work, also using complements such as Zotero.

- Tags in a specific area are more valuable than in general contexts (with more meanings), because a specific context provides additional value: its own specificity and the one given by other tags in its context (Alonso Arevalo, 2009).

- Enables one to visualize the actual interests of a researcher through his tag cloud.

- Favors team work by matching synergies of a specific research group.

- Makes the spreading of ideas between interdisciplinary fields easier.

Diigo offers new opportunities for learning and building up knowledge, because when a user subscribes to watchlists of important researchers or scientists they can learn by following their bookmarking system. This is achieved not only through contents, since the visitor can catch the researcher's meta-learning process, or the ways he has learnt, turning them into itineraries of efficient thought that can be extrapolated, but also by careful consideration to develop or interpret the meaning of each bookmark and build knowledge cooperatively (Singh, Hawkins, \& Whymark, 2007). Diigo provides students with a valuable opportunity to learn about their own learning process and identify the aspects of the information they find relevant. It also make students become aware of their own criteria when they have to tag or categorize them. The very act of refining and defining the tags they use is a valuable feedback in itself.

Professors can provide the students with an appropriate structure to guide them towards the discovery of their own learning. This is the reason why the use of significant personal tags should be considered as metadata, so the cognitive abilities students apply when they learn become visible. The simple act of tagging a resource or a learning object indicating its objective can help students to think about their own cognitive style or the way they learn. Diigo allows students and researchers to learn from other members of the learning community when they adopt as their own some of the more efficient bookmarking structures and strategies used by other colleagues or professors with whom they share resources. It helps them to think about their learning process or metacognitive development through analysis of how each individual uses them according to their particular learning styles.

Diigo also enhances the development of the following wide-ranging capabilities:

a) Information search and management. Due to the great amount of information that can be found on the web, it is necessary to make a selection in order to detect and distinguish true, reliable, and rigorous information. Using Diigo can be a time-saving strategy, as it involves identifying what is considered important for a specific community and taking as a starting point the opinions of each member of the group. Using it enhances the development of the very much in demand digital competencies, such as information search and management. Furthermore, the very act of marking a page means that the user is categorizing, summarizing, and assessing the information it contains. When students are taught how to mark resources, they are being given a powerful strategy to know how to distinguish valid information by applying criteria to filter it.

b) Information analysis. Diigo tagging is based on a particular way of understanding information, starting from mental maps. An interesting didactic application to be implemented in learning contexts could be an exercise that involves collecting items in order to analyze the value of a web page or a web resource, such as authorship, reliability, scientific rigor, or educational potentiality, and ask students to justify their decision to select it as interesting or useful and share it with others. 
c) Categorizing information. Its ability to categorize, organize, establish relationships, describe resources, etc., can be helpful to learn specific content of any discipline, because it favors the understanding of key concepts and their categorization.

Finally, on the topic of social building of knowledge, by using Diigo as a social bookmarking tool, the contributions of each member of a learning community are enhanced. Building knowledge collectively makes its advance and development possible, especially in a learning and scientific context. Users take part by establishing and sharing what they know from different approaches. By using Diigo, you can learn from others. By following others' bookmarked itineraries, both professors and students can share information in a two-way exchange, or a whole learning community (researchers, teaching centre, etc.) can take part in a collaborative project, which can be developed virtually, overcoming space-time barriers. Also, a collaborative online database is a cognitive tool that enhances the knowledge building process (Rosen \& Rimor, 2009, p. 189.)

\section{Examples of Academic Use}

Besides the benefits and advantages that Diigo offers, there are real academic situations where this Web 2.0 tool is used successfully. In Table 1, some case studies have been collected and described.

\section{Table 1: Examples of academic use of Diigo}

$\begin{array}{cl}\text { University/ College } & \text { Knowledge area/ Research grou } \\ \text { Kansas State U. } & \text { Cultural Anthropology. Digital } \\ & \text { Ethnography Working Group }\end{array}$

Northeast Lakeview Col- Introduction to Sociology lege

Master

Master

Concordia U.
Technology Information
Center for Administrative
Leadership
(TICAL)

University of Sheffield
Photojournalism and documentary

Teacher Education

NEA. National Education Association

Teacher Education Program

History

\section{Application/ Students}

In a class of 200 students, they use Diigo in order to keep track of teaching resources.

Online collaborative research replaces the traditional manual. Students research about the concepts and add comments on them.

\section{It is used as a dynamic way of sharing} links and resources for developing collaborative group research projects. Each project has its own tag and all the students together add links to it. After that, the material is distributed in the classroom and each one has to read selected papers and then develop a summary that will be shared among the other students. In this way, all the class will have a global idea of the research issue.

It is used for sharing and comment links and resources of specific issues.

- Researching about interesting issues. Resource and bibliographic references searching.

To share resources specific to course work using the List tool

Two classes of 10 students per class. They developed an online resources list for their weekly seminars over a semester. 
The efforts of many teachers and researchers in improving their practice also results in the creation of user communities where they can comment and share experiences. For example, in Diigo Groups there are many communities focused on the possible applications of Diigo to education. Two of these are:

- “Technology Enabled Learning \& Teaching @ UNSW", which is focused on applications, examples, case studies and papers discussing the use of contemporary educational technologies in university learning and teaching practice. 109 users belong to this group, and it has 1955 resources bookmarked.

- "Diigo in Education", where their members share their classroom use cases, ideas, reviews, features, and wishlists for making Diigo a great resource and platform in teaching and learning. In this case, 4889 users belong to it sharing 4063 bookmarked resources.

\section{Comparative Analysis of SBS}

As previously stated, the main goal of SBS is resource bookmarking and description. This involves storing a link and describing it using metadata. Storage first started in 1993 as something new inside the 'Mosaic' browser. In this case, link storage was called 'Hotlists'. Then, with Netscape browser (version 1.0, December 1994) this storage of links was called 'Bookmarks' and was also called 'Favourites' in Internet Explorer (July, 1995). There were also some proposals such as SyncIT (1998) to synchronize the favourites of a browser with a web storage system.

The first collaborative attempts regarding links were links directories, where taxonomies were elaborated. Some of these are relevant such as Open Directory Project, Zeal or others for commercial purposes as Yahoo (Hammond et al., 2005.) These bookmarks were improved so much to the degree that javascript was added giving rise to the so-called 'bookmarklet.' These are simple links that can be aggregated as favorites, but they incorporate javascript code providing them with extra functions.

After these attempts, social managers of links were created. These non-randomly stored links were found by means of crawlers or robots, and if not registered, were identified with tags and assessed by users, making them available for others. In this context, in 1996, itList surfaced, which included public and private bookmarks. Then similar services such as Backflip, Blink, BookmarkBox, Bookmarks Plus, Clickmarks, Clip2, Murl, MyPassword.net, Oneview, Hotlink and Quiver appeared (Cf. http://www.llrx.com). Some of these services stopped working after the dot-com boom, but they allowed for the organization of bookmark folders, forwarding those marked by e-mail, along with some additional functions. Finally, a new era began in 2003 with the coming of Delicious and the rest of SBS that are described below. Here there are various social bookmarks classified by marked resource.

In Table 2 there are websites such as Digg, Reddit and Propeller that are focused on the social bookmarking of items associated with news (politics, sports, technology, etc.) These services offer headlines of each piece of news and foster users' comments. These are different from general social bookmarks because they are focused on specialized literature and contributions in blogs more than on websites. As a consequence, they can be an important source of news and they also offer the possibility of taking part in discussions by adding personal comments about interesting news. 
Table 2: Comparing SBS

\begin{tabular}{|c|c|c|}
\hline \multicolumn{3}{|c|}{ Table 2: Comparing SBS } \\
\hline Type of resource & Bookmarks & Description \\
\hline General web links & $\begin{array}{l}\text { Blackflip (1999), Balatarin (2006), } \\
\text { Blinklist (2005) }\end{array}$ & $\begin{array}{l}\text { Web sites references through bookmarks } \\
\text { (the object of study in this article.) Most of } \\
\text { them allow for synchronization with } \\
\text { del.icio.us and import browser favorites. } \\
\text { They enhance bookmarks export to be used } \\
\text { in other SBS. }\end{array}$ \\
\hline News & $\begin{array}{l}\text { Digg.com (2004), Meneame.com } \\
\text { (2005), Reddit (2005), SpicyBookmark } \\
\text { (n.d.), Propeller (2006), Newswine } \\
\text { (2005) }\end{array}$ & $\begin{array}{l}\text { Focused on the social bookmarking of spe- } \\
\text { cialized literature, news and blogs contri- } \\
\text { butions. }\end{array}$ \\
\hline $\begin{array}{l}\text { Bibliographical refer- } \\
\text { ences }\end{array}$ & $\begin{array}{l}\text { 2collab (2007), Mekentosj Paper } \\
\text { (2001), Mendeley (2007), My NCBI } \\
\text { (n.a.) and Zotero (2006) }\end{array}$ & $\begin{array}{l}\text { In these social net of references, folders } \\
\text { can be shared, users can create groups, start } \\
\text { discussions, include the researchers' CV } \\
\text { and profile. If a reference of a specialized } \\
\text { area has been aggregated to the manager by } \\
\text { many authors, it becomes more and more } \\
\text { 'popular' because many experts in that area } \\
\text { have found it interesting. It can also help to } \\
\text { find out what other researchers interested } \\
\text { in that consulted resource are reading and } \\
\text { make digital libraries more personal, soci- } \\
\text { able and integrated places. }\end{array}$ \\
\hline Pictures & $\begin{array}{l}\text { Flickr (2004), vi.sualize.us (2007), we- } \\
\text { heartit.com (2008) }\end{array}$ & \\
\hline Blogs & Frassle (2003) & \\
\hline
\end{tabular}

\section{Diigo, Delicious and Conventional Bookmarking}

Comparing Diigo's tool with conventional bookmarking tools and Del.icio.us will help to understand better Diigo's innovation, which is the most used and widespread bookmarking tool (Diigo, 2006.)

One of Diigo's strong points is its highlighting and annotation functionalities (by Sticky notes), which del.icio.us and conventional bookmarking lack.

Table 3 shows comparative functions of these tools: 


\begin{tabular}{|l|c|c|c|}
\hline \multicolumn{4}{|c|}{ Table 3: Comparative between Diigo, Traditional Bookmark and Delicious } \\
(Adapted from Diigo help)
\end{tabular}

It can be inferred from the table above that Diigo has a set of functions that enhance its versatility and capacity as an SBS against other consolidated tools, such as Delicious, and especially conventional bookmarking. Diigo is competing with Delicious (SBS reference), especially in countries like India, The United States, China and Germany as shown in Figure 6, which shows the distribution of the base of the Diigo users in these countries, the intensity of use, and the ranking of the service in that country. 


\begin{tabular}{lrrr|}
\hline Country & $\%$ User & $\%$ Pageviews & Rank in country \\
\hline India & $34.8 \%$ & $46.1 \%$ & 5192 \\
\hline EUSA & $19.8 \%$ & $14.6 \%$ & 38514 \\
$\square$ China & $7.1 \%$ & $5.2 \%$ & 35034 \\
$\square$ Germany & $5.3 \%$ & $6.0 \%$ & 47855 \\
$\square$ Pakistan & $3.6 \%$ & $4.6 \%$ & 11127
\end{tabular}

Figure 6: Diigo users' database by countries (Adapted from Dataopedia.com)

Some of the mentioned functions, such as highlighting, aggregation of notes, synchronization with references marked with other SBS (del.icio.us, Blinklist, Connotea, Furl and Simpy), have led to positive assessment. This is shown in Figure 7, where a comparison between daily worldwide visits to Diigo vs. del.icio.us is displayed using a Google Trend bar:

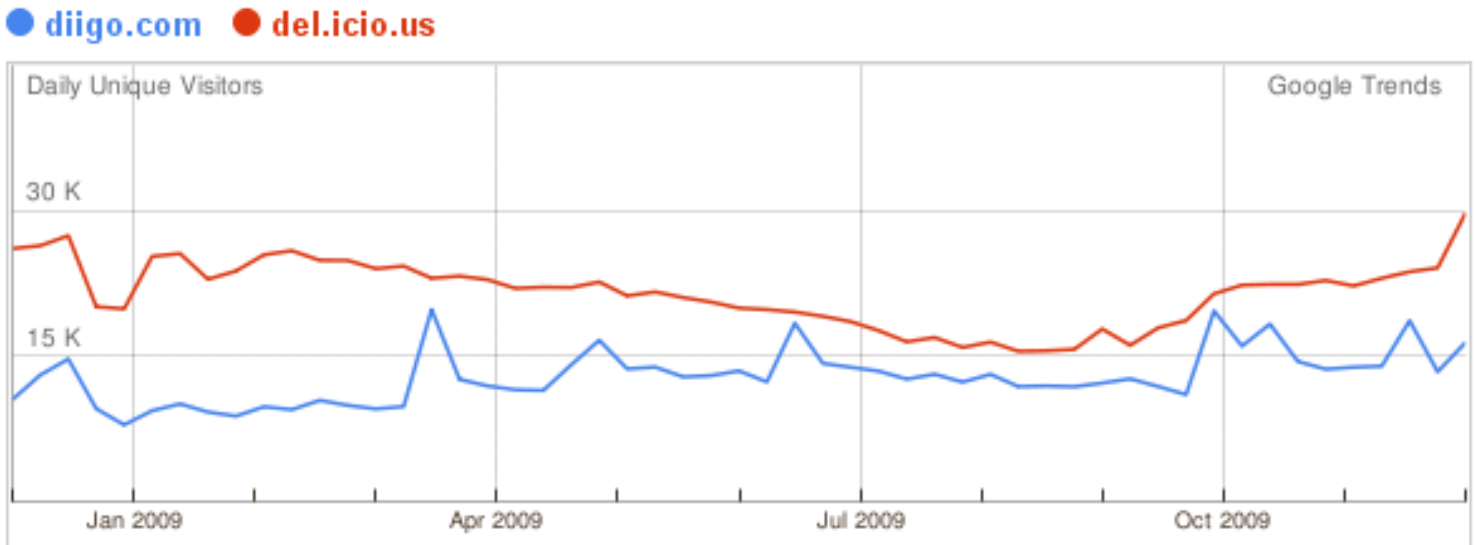

Figure 7: Daily traffic during the year 2009 in Diigo and del.iciou.us (Google Trends)

\section{SWOT}

The next table displays a synthesis of the most relevant aspects of Diigo tool after applying SWOT Analysis methodology (Strengths, Weaknesses, Opportunities, and Threats), based on the analysis of the content of the assessment of a training community (consisting of 30 members). In the following display, the great contributions of Diigo to favor collaborative research processes, detect technical restrictions that it still has, and enumerate the potential applications that are still to be explored can be identified 


\begin{tabular}{|c|c|c|}
\hline \multicolumn{3}{|c|}{ Table 4: SWOT analysis } \\
\hline & Strengths & Weaknesses \\
\hline $\begin{array}{l}\text { Internal } \\
\text { analysis }\end{array}$ & $\begin{array}{l}\text { Technical aspects: } \\
\text { - Intuitive interface, close to human relational } \\
\text { thinking } \\
\text { - Synchronization with del.icio.us, blinklist } \\
\text { - } \text { Promotion of user interaction with the con- } \\
\text { - Excellent tool to combine notes and book- } \\
\text { marks } \\
\text { - Quick execution with a comprehensive links } \\
\text { search engine } \\
\text { Accessibility: } \\
\text { - Marked resources on the web that can be } \\
\text { found from anywhere } \\
\text { - The bookmarking of resources can be pri- } \\
\text { vate or public } \\
\text { Communication: } \\
\text { - It allows adding comments about the visited } \\
\text { webs, identifying who did it and what was } \\
\text { highlighted. } \\
\text { - Cloud tags show the topics the user is inter- } \\
\text { ested in. } \\
\text { It makes efforts dynamic and profitable by } \\
\text { allowing to see others' assessment about } \\
\text { specific webs }\end{array}$ & $\begin{array}{l}\text { Technical aspects: } \\
\text { - It makes some browsers slower. } \\
\text { - Not very dynamic, it takes 20" to } \\
\text { finish a task. } \\
\text { - It needs to start a session after } \\
\text { marking each new resource. } \\
\text { - Not all the utilities, colors, etc. can } \\
\text { be customized. } \\
\text { - It tracks the user that is bookmark- } \\
\text { ing. } \\
\text { - It "compels" to share. } \\
\text { It is necessary to create a new ac- } \\
\text { count identifying the user, who } \\
\text { cannot be anonymous. } \\
\text { Communication: } \\
\text { - It doesn't allow an instant feedback } \\
\text { between users that add comments. }\end{array}$ \\
\hline & Opportunities & Threats \\
\hline $\begin{array}{l}\text { External } \\
\text { analysis }\end{array}$ & $\begin{array}{l}\text { A research tool } \\
\text { - It is extremely useful for on line research. } \\
\text { - It enhances collaborative research projects. } \\
\text { - It helps to manage research tasks: selection } \\
\text { and categorization of interesting biblio- } \\
\text { graphical sources. } \\
\text { - It emphasizes the collaborative dimension } \\
\text { based on the shared use of bookmarks } \\
\text { A learning tool } \\
\text { - It shows expert bookmarks systems, whose } \\
\text { itineraries can be considered as a reference. } \\
\text { - It makes cognitive abilities visible for orga- } \\
\text { nizing and categorizing information. } \\
\text { - It develops competencies - search, man- } \\
\text { agement, analysis and categorization of in- } \\
\text { formation. } \\
\text { Social building of knowledge } \\
\text { - The total amount of efficient shared book- } \\
\text { marking strategies enhance knowledge } \\
\text { learning and development }\end{array}$ & $\begin{array}{l}\text { Social semantics vs. confusion } \\
\text { - A lack of homogeneity and agree- } \\
\text { ment on the definition of tags. It } \\
\text { leads to ambiguities. } \\
\text { Constant updating and change } \\
\text { - The constant improvement of SBS } \\
\text { features make them obsolete and } \\
\text { other new systems arise dispersing } \\
\text { users, forcing them to constantly } \\
\text { migrate. } \\
\text { - Incompatibility or lack of entire } \\
\text { permeability (import-export) among } \\
\text { all the SBS. } \\
\text { Incipient developments to combine } \\
\text { its use with conventional browsers, } \\
\text { which enhances accessibility }\end{array}$ \\
\hline
\end{tabular}




\section{Conclusions}

Virtual environments or communities that foster learning and research from a collaborative approach and introduce new ways of working that highlight the social dimension of knowledge are becoming extremely valuable. By allowing interaction and cooperative problem resolution processes, they become a collaborative social space (Del Moral \& Cernea, 2006.) In addition to this, the use of SBS helps to contextualize the learning process and enhances its meaning.

Virtual communities become closely linked groups because each member tries to achieve common objectives, turning the groups into powerful communities with solid internal relationships. Thus, they become important social networks that have great advantages derived from each member's assets.

Collaborative tagging and/or social bookmarking of learning resources foster a context of personalized social learning. From a constructivist point of view, tags shared by users become significant learning resources providing the teaching/learning process and on-line research with a social dimension. The user gets consciously involved in the creation of tags assigning new meanings to the shared resources. This process generates new collaborative learning contexts (Cernea, DelMoral \& Labra, 2008.)

Virtual environments where SBS are used are based on constructivist principles, which foster the migration from an intrapersonal learning process to an interpersonal process with a social dimension.

Personal interactions that arise spontaneously through shared annotations make and strengthen the collaborative learning process and make users continuously think about the relationship between the resource and the tag. As a consequence the conceptual socialization of learning resources is enhanced (Kohlhase \& Reichel, 2006).

Diigo particularly fosters the cohesion of research groups by monitoring information tagged by different users. It adds more dynamics to the organization, communication and updating of bibliographical references concerning a specific theme. It helps to manage information recovered at the different stages of the research process, along with other tools such as Zotero, in addition to fostering collaborative work by enhancing synergies inside the group while helping to build knowledge cooperatively.

Diigo is a metacognitive tool because it displays different ways to learn, think, and build knowledge of each individual by showing the information each member selects, along with his or her preferences and strategies to organize and categorize it. In fact, by sharing with others this specific personal ability, its value is enhanced for the virtual community because it allows other members to opt for more efficient itineraries, maximizing their potentials as a whole.

In virtual learning contexts, Diigo is extremely useful to develop digital competences directly related to information search, management, analysis and categorization.

From a technical point of view, this tool is a step forward compared to other SBS because it has improved functionalities. Among these, it must be taken into consideration the possibility of highlighting contents and adding floating sticky notes on the web pages. Both types of annotation will be available for other users, which favors collaborative work by making comments, corrections, or explanations. As it has already been said above, apart from the own functionalities of the tool, there are complements that make individual and collective work easier such as toolbars, favorite export and import from and towards other bookmarking toolbars or even a version for an iPhone application. Further development is to be expected so that a more visual version of the tool becomes a reality together with a comprehensive exploitation of its semantic capacities that allows for the suggesting of tags or the finding of users depending on their bookmarking habits. 


\section{References}

Alonso Arevalo, J. (2009). Gestores de referencias sociales | Universo Abierto (Social Bookmarking Systems). Retrieved December 23, 2009 from http://www.universoabierto.com/2562/gestores-dereferencias-sociales/

American Association of School Librarians (2009). Best web sites for teaching and learning. Retrieved December 31, 2009 from http://www.ala.org/ala/mgrps/divs/aasl/guidelinesandstandards/bestlist/bestwebsitestop25.cfm

Bateman, S., Muller, M. J., \& Freyne, J. (2009). Personalized retrieval in social bookmarking. Proceedings of the ACM 2009 International Conference on Supporting Group Work, pp. 91-94, Sanibel Island, Florida, USA. ACM.

Cattuto, C. (2006). Semiotic dynamics in online social communities. The European Physical Journal C Particles and Fields, 46, 33-37.

Cernea, D. A., Del Moral, M. E., \& Labra Gayo, J. E. (2008). SOAF: Semantic indexing system based on collaborative tagging. Interdisciplinary Journal of E-Learning and Learning Objects, 4, 137-150. Retrieved December 31, 2009 from http://www.ijello.org/Volume4/IJELLOv4p137-149Cernea.pdf

Del Moral, M. E., \& Cernea, D. A. (2006). Wikis, Folksonomías y Webquests: Trabajo colaborativo a través de Objetos de Aprendizaje (Wikis, Folksonomies and Webquests: collaborative work through Learning Objects). Proceedings of III Simposio Pluridisciplinar sobre Diseño, Evaluación y Descripción de Contenidos Educativos Reutilizables (SPDECE06) Oviedo, 2006.

Diigo. (2006). Diigo is about social annotation. Retrieved December 31, 2009 from http://www.diigo.com/help/about

Hammond, T., Hannay, T., Lund, B., \& Scott, J. (2005). Social bookmarking tools (I). D-Lib Magazine, 11. Retrieved December 26, 2009 from http://dlib.org/dlib/april05/hammond/04hammond.html\#3

Heymann, P., Koutrika, G., \& Molina, H. G. (2008). Can social bookmarking improve web search? WSDM '08: Proceedings of the International Conference on Web Search and Web Data Mining, pp. 195-206, New York, NY, USA. ACM.

Kolay, S., \& Dasdan, A. (2009). The value of socially tagged urls for a search engine. WWW'09: Proceedings of the 18th International Conference on World Wide Web, pp. 1203-1204, New York, NY, USA. ACM

Kohlhase, A. \& Reichel, M. (2006). Embodied, constructionist learning: Social tagging and folksonomies in e-learning environments. mICTE 2006. Conference Proceedings

Mathes, A. (2004). Folksonomies - Cooperative classification and communication through shared metadata. Retrieved December 22, 2009, from http://www.adammathes.com/academic/computer-mediatedcommunication/folksonomies.html

Millen, D. R.; Feinberg, J., \& Kerr, B. (2005). Social bookmarking in the enterprise. Queue, 3(9), 28-35.

Millen, D. R.; Whittaker, S., \& Yang, M. (2007). Social bookmarking and exploratory search. ESI, 5.

Rosen, Y., \& Rimor, R. (2009). Using a collaborative database to enhance students' knowledge construction. Interdisciplinary Journal of E-Learning and Learning Objects, 5, 187-196. Retrieved from http://www.ijello.org/Volume5/IJELLOv5p187-195Rosen671.pdf

Singh, G., Hawkins, L., \& Whymark, G. (2007). An integral model of collaborative knowledge building. Interdisciplinary Journal of E-Learning and Learning Objects, 3, 85-104. Retrieved from http://ijello.org/Volume3/IJKLOv3p085-105Singh385.pdf

Smith, G. (2004, August 3). Atomiq: Folksonomy: Social classification. Retrieved 7 April 2010 from http://atomiq.org/archives/2004/08/folksonomy social_classification.html 
Zubiaga, A.; Martínez, R., \& Fresno, V. (2009) Getting the most out of social annotations for web page classification. Proceedings of the 9th ACM Symposium on Document Engineering, pp. 74-83, Munich, Germany. AC

\section{Biographies}

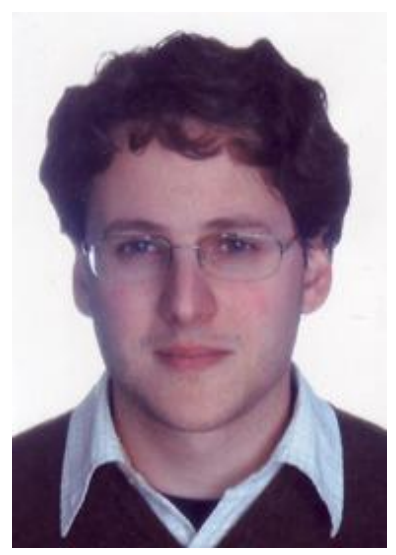

Enrique Estellés Arolas. Graduated in Computer Science by the CEU-Cardenal Herrera University in 2007. He is a PhD student, member of the Mathematics, Physics and Computational Sciences department of the CEU-Cardenal Herrera University. His research interests are centered on new technologies applied to education, e-learning, the socio-technical theory and lightweight methodologies.

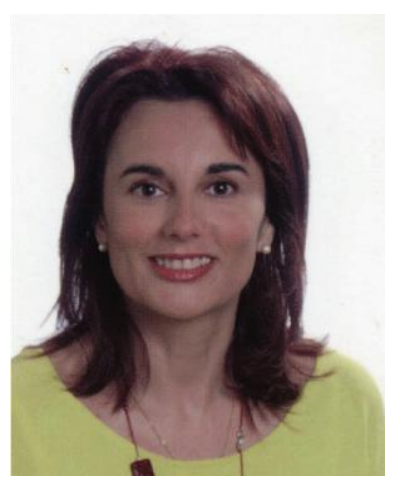

$\mathbf{M}^{\mathbf{a}}$ Esther Del Moral Pérez received the PhD in Education Science in 1994, where she is Professor of New Technologies applied to Education in the Department of Education of Oviedo University. She also has a Master in Educational Technologies since 2000. Leader of Tecn@ Research Group, her research interests include designing and testing hypermedia learning resources, e-Learning and cognitive styles and the networks and Web applications in the learning technologies. Visiting researcher in University of Calgary (Canada), University of Friebourgh (Germany), University of Poitiers (France) and University of Genova (Italy).

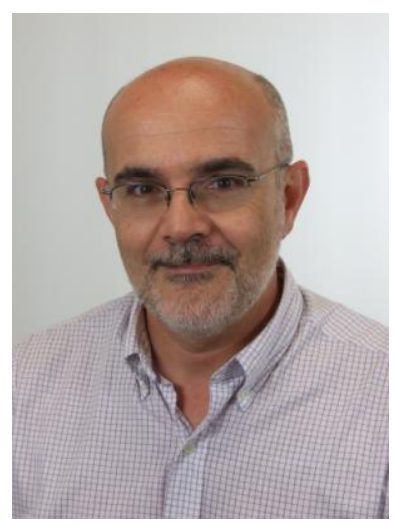

Fernando González Ladrón de Guevara received the PdD in Industrial Engineering in 2001. He is Professor of Operations Managements and Information Systems in the Business and Economics Department of Technical University of Valencia. His research interests include eLearning and implementation of information systems, developed in ITIO (Integration of Information Technologies in Organizations). Visiting professor and researcher in University of Santander (Colombia), University of S. Martin de Porres (Peru) and Sustentare Business School (Brazil). 